\title{
CHALLENGES IN OIL AND GAS INDUSTRY FOR MAJOR FIRE AND GAS LEAKS- RISK REDUCTION METHODS
}

\author{
Rekhapalli Srinivasa Rao ${ }^{1}$, KVSG Murali Krishna ${ }^{2}$, Ayila Subrahmanyam ${ }^{3}$ \\ 1. Research Scholar, JNTUK University, Kakinada, Andhra Pradesh, India, rekhapalli_sri@yahoo.co.in \\ 2. Professor of Civil Engineering, JNTUK University, Andhra Pradesh, India, kvsg.muralikrishna@gmail.com \\ 3. Lecturer, Andhra Polytechnic, Kakinada, ayilasub@yahoo.co.in
}

\begin{abstract}
Oil and gas industries play a major role to fulfil the human requirements of daily needs including cooking, transportation etc. With the consumption, demand on production of petroleum products and plant operations in summer months and extreme weather conditions to operate with high risk. Lack of gas leaks detection system and uncontrolled gas venting through flare stacks with black smoke are major threats for the plant as well as people working in the industry or neighbourhood. The heat index is an index that combines air temperature and relative humidity in an attempt to determine the human-perceived equivalent temperature, how hot it feels. During summer months with high heat index, combating major fire in industries is present burning problem. As per heat index chart above $52^{\circ} \mathrm{C}$ all works should be stopped according to safety requirements. But even by using well advanced fire gear and ice jackets and following work to rest period ratio of 20:10 minutes, is difficult to combat fire. This paper explains the challenges facing now a days in oil and gas industries when an extreme weather conditions like high winds from cyclones, major gas leaks and combating fire in summer months. Also explains the risk reduction from major fire and gas system if any major or minor gas leaks in industry. Establishing safety systems like gas leaks detection equipment, deluge and fire water system as well as mobile fire protection systems. And safety devices such as pressure reliefs, incinerators and flare stacks etc. Flaring is high temperature oxidation process of combustion of waste gases venting from any process. By adopting new technologies of advanced process control with automation of steam control system, black carbon or soot from flare stacks can be minimized and save human being health from dangerous particulate matter emission from sooty flares.
\end{abstract}

Key words: Emission, flare, gas leak, hazard, heat index

$* * *$

\section{INTRODUCTION}

An industrial safety system is a counter measure crucial in any hazardous plants such as oil and gas plants. They are used to protect human, plant, and environment in case the process goes beyond the control margins [1]. Hazards monitoring should be carried out both within the organization itself and through external agencies. Internal monitoring may be conducted by internal but independent functions, such as pressure vessel inspection, and by consultants. External monitoring takes place through the activity of interest groups and government agencies [2]. In oil and gas industries, gas leaks from the valves, flanges, equipments and instruments in live process units operating with high pressures, are high risk of fire hazard and more prone to vapour cloud explosion. A deadly toxic gas like
Carbon Monoxide (CO) is having no smell and accumulates on the ground level may dangerous to plant operating personnel. Volatile Organic Compounds (VOC) from hydrocarbon storage tanks are too accountable for the fire hazard if improper sealing system for the tank roofs. In Middle East countries like Qatar, Saudi, etc., during hot summer months which comes in July and August, ambient temperatures recording $49-53 \mathrm{degC}$ in peak. The heat index (HI) is an index that combines air temperature and relative humidity in an attempt to determine the human-perceived equivalent temperature, how hot it feels. According to heat management chart (figure-1) and government regulations, work to rest period guidelines should follow by all work force in the industry. 


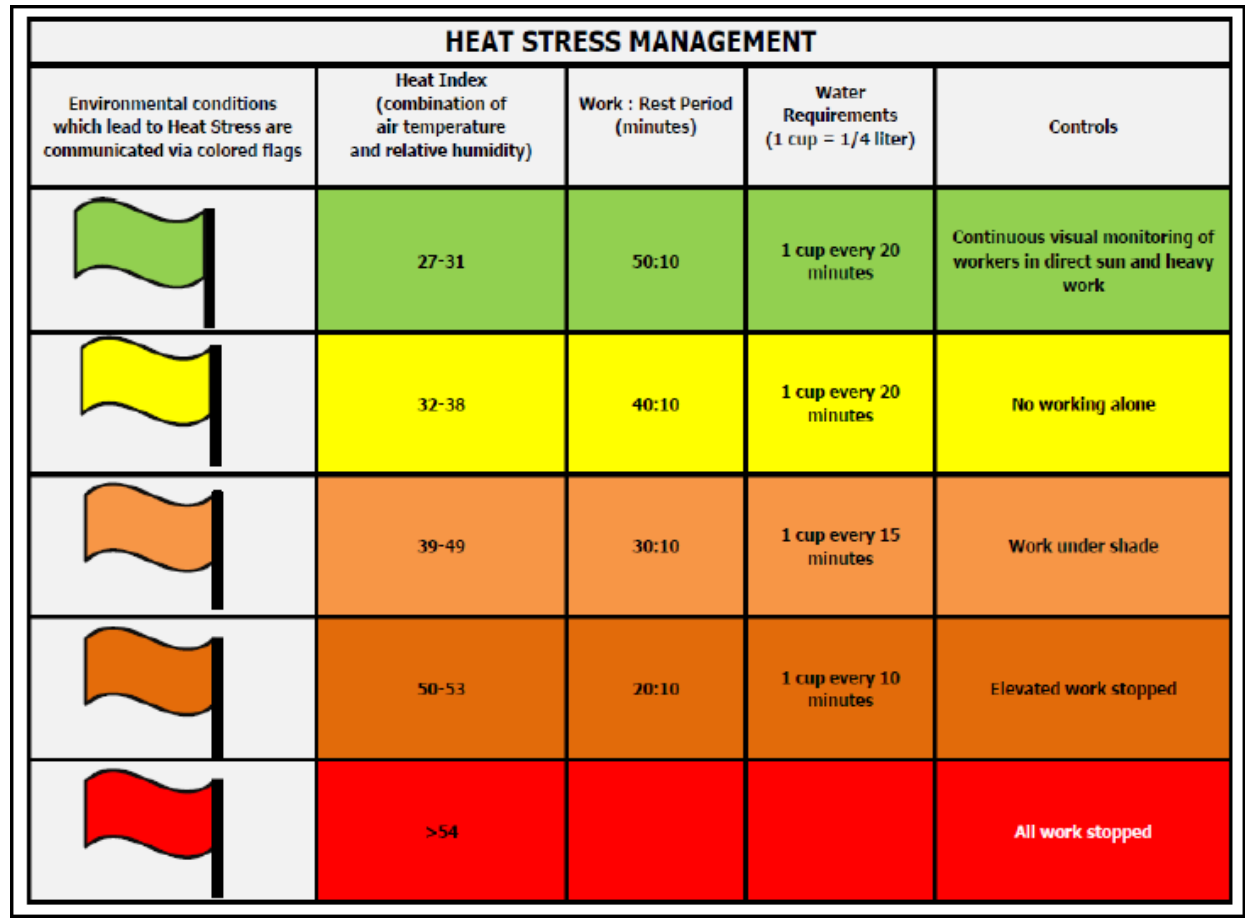

Figure 1: Heat Stress Management

In Oil and Gas industries fire is a common hazard and emergency response team with fire fighting equipment is always stand by. But during summer months with high heat index, in case of any major fire, combating fire is a big challenge.

In case of any major gas leaks from catastrophic failure of the equipment or pipelines, which may leads to disaster. A well designed process plant equipped with safety system like pressure relief devices, flare stacks for venting waste gases. Poor monitoring of gas leaks and poor maintenance of the equipment inspections in process area can leads to uncontrolled release of explosive gases like methane, ethane etc.,

Flaring is a technique used extensively in oil and gas industry to burn unwanted waste gases. Flaring creates pollutant emissions such as particulate matter in the form of soot or black carbon. Smoke results from combustion, depends on waste gas components, quantity and distribution of combustion air. Flare stacks are used in industries are often assisted with steam to ensure complete combustion and to avoid any unburnt hydro carbons. In this process, flares are often sooty (figure 2) due to insufficient steam [3]. As of the end of $2011,150 \times 10^{9} \mathrm{~m}^{3}$ of associated gas are flared annually. That is equivalent to about $25 \%$ of the annual natural gas consumption in the United States or about $30 \%$ of the annual gas consumption in the European Union [4].

The amount of flaring and burning of associated gas from oil drilling sites is a significant source of carbon dioxide $(\mathrm{CO} 2)$ emissions. Some $400 \times 106$ tons of carbon dioxide are emitted annually in this way and it amounts to about $1.2 \%$ of the worldwide emissions of carbon dioxide [5]

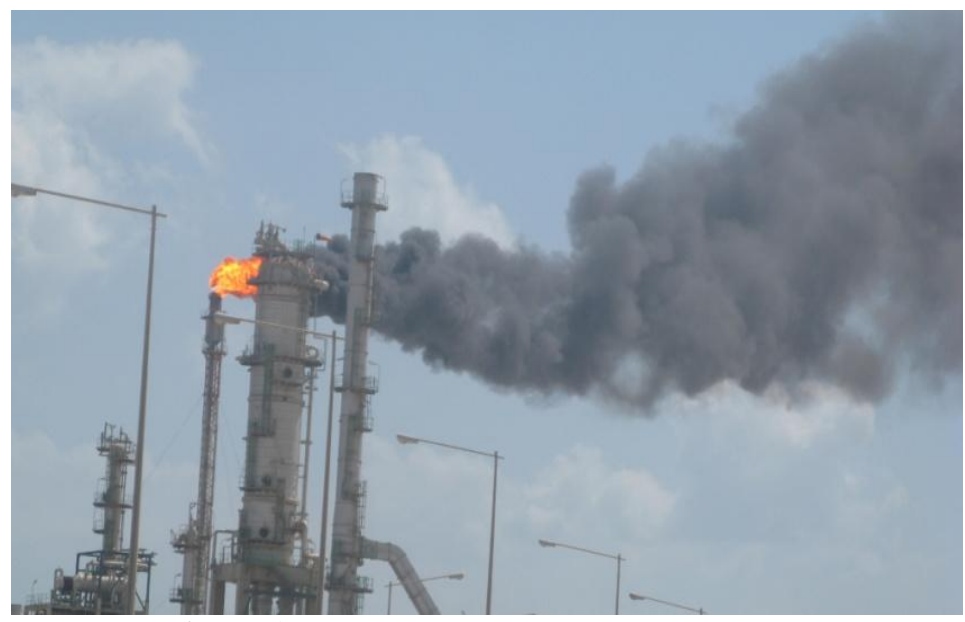

Figure 2: Uncontrolled flaring without steam 
Unlike carbon dioxide and other greenhouse gasses, which can survive in the atmosphere for decades and centuries, black carbon has a relatively short life span of approximately one to two weeks. Black carbon is part of a group of pollution sources known as Short-Lived Climate Forcers (SLCFs), including methane gas and ozone, which are produced on earth.

\section{PROCESS HAZARD \\ ANALYSIS REQUIREMENTS:}

Each facility should conduct hazard evaluation on each of the existing plant units. Hazard Evaluation methods will depend on nature and complexity of the process (figure 3).

- The hazards of the process.

- Previous incidents which had a likely potential for a catastrophic consequences in the workplace.

- Consequences of failure of engineering and administrative control.

- Human factors.

- A qualitative evaluation of a range of the possible safety and health effects of failure of control on employees in the work place should be completed.

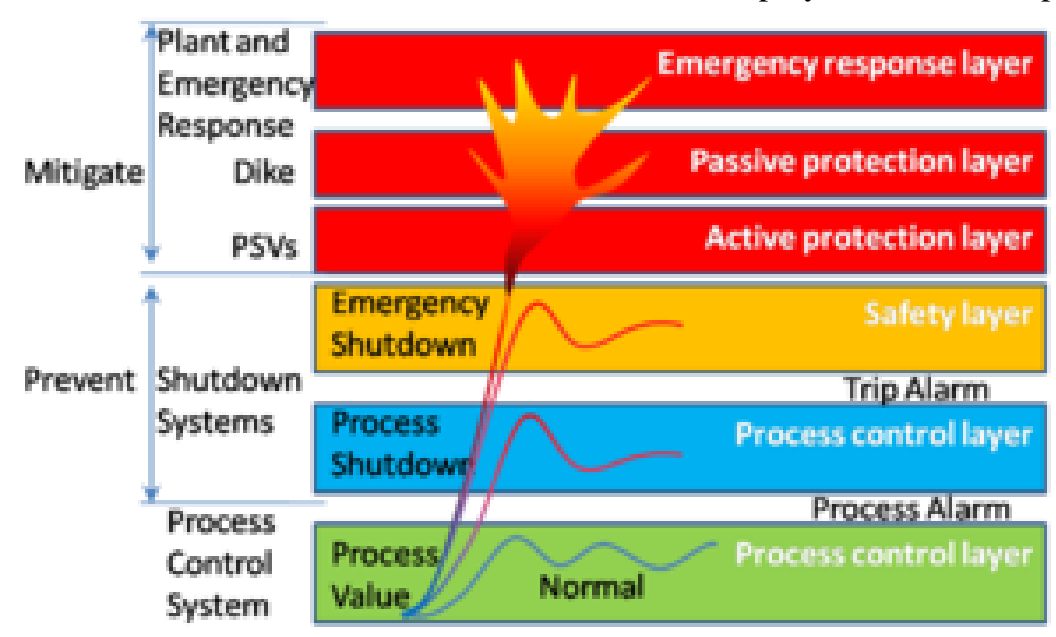

Figure 3: Safety layer protection

\section{METHODOLOGY FOR PROCESS HAZARD}

\section{EVALUATION:}

HAZOP, What if check list, and safety reviews are approved methods for project PHEs.

To conduct process hazard analysis, the following process safety information must be compiled.

- Hazards of highly hazardous chemicals: Material Safety Data Sheets (MSDS) which are required for all hazardous materials as defined in the OSHA hazard communication regulations[29 CFR 1910$1200(\mathrm{~g})]$

- Simplified process flow diagrams are required for all processes.

- Maximum intended inventories must be documented only for flammable and/or toxic chemicals.

- Safety operating limits: Each facility must document the critical operating parameters. Critical operating parameters are parameters, which if exceeded could result in a major incident.

- Electrical classifications: Drawings must be maintained that illustrates the electrical classification for various areas of the plant.

- Relief systems: All relief devices including relief valves, rupture disks, pressure/vacuum valves and thermal valve relief valve shall have associated design information. Relief system such as collection headers, knock out drums/pots, flame arrestors, incinerators, flare stacks etc., shall also have design information provided.

- Safety systems: Safety interlocks and safety shut down, Gas monitoring systems, Deluge and fire water system as well as mobile fire protection system, fire and explosion suppression systems, safety showers, breathing air systems, public address system and other communication systems used during emergencies.

\section{CONCLUSIONS AND RISK REDUCTION METHODS:}

During high heat index conditions, fire fighting team faces very difficult situations as they wear fire fighting gear itself creates lot of heat from inside. Usage of ice jackets, and continuous water showering on fire fighting teams and frequent change of fire fighting team as per heat stress management chart i.e., 20 minutes fire fighting and 10 minutes rest period replace with another team can serve better to come out from emergency fire conditions. Continuous heat index monitoring (figure 4) from weather reports will give quick information to emergency response team. 


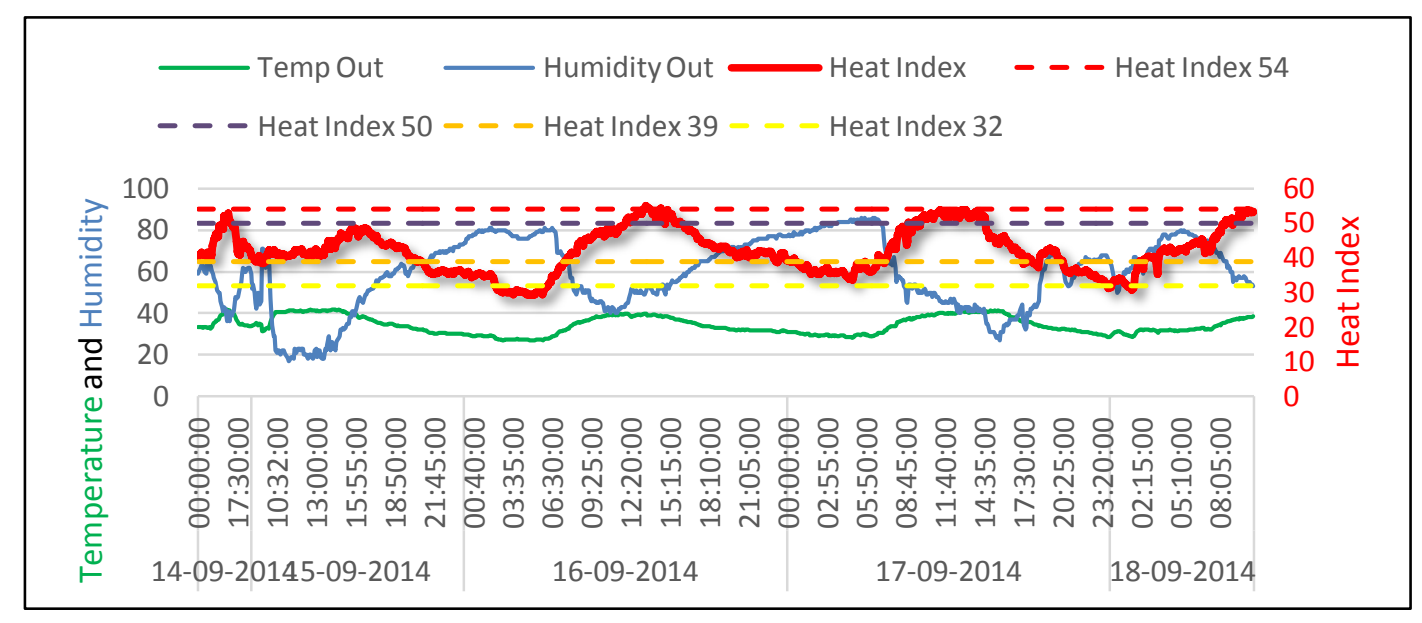

Figure 4: Heat index monitoring chart

Deluge system: This system contains fire water piping charged with water with shut off valve, around high pressure compressors and pumps etc., where more prone to hydrocarbon leaks and fire hazard, will be activated in case of any fire which melt the bulb fixed downstream of the shut off valve, will inject water on to the fire and ceases fire.

Fire water system and automatic foam injection system on storage tank roofs are emergency fire protection systems.

Gas detectors with flash lights on top of the equipment installation in process equipment area and connected to centralized control room for alarming emergency control panel gives immediate information to the control room operator in case of any hydrocarbon or toxic gas release.

Flare stacks must be equipped with steam flow control valve and ultrasonic flow measurement to find out the amount of hydrocarbon venting. Automatic control of soot by adopting ratio controller with feed forward control action on steam flow control valve will inject steam into flame zone in case of heavy smoke forms. This automatic control system keeps always zero soot formation from the flare stack in any emergency situation.

\section{ACKNOWLEDGMENT}

I express my profound gratitude and sincere thanks to my research supervisor Dr KVSG Murali Krishna, Professor of Civil Engineering, JNTUK University, Kakinada, Andhra Pradesh, India for his valuable and dynamic supervision throughout the progress of this work.

\section{REFERENCES}

[1] http://en.wikipedia.org/wiki/Industrial_safety_system [2] Lee's Loss Prevention in the process industries: Hazard identification, assessment and control.

[3] Rekhapalli Srinivasa Rao and KVSG Murali Krishna, "Simulation study to minimize soot and unburnt hydro carbons from steam assisted flares and Health effects of
Soot", International Journal of Science and Research [IJSR], Volume 3, Issue 10, October 2014.

[4] Estimated Flared Volumes from Satellite Data, 20062010. http://web.worldbank.org/

[5] http://www.pbl.nl/sites/default/files/cms/publicaties/pbl2013-trends-in-global-co2-emissions-2013-report1148.pdf (2013) 